\title{
CONCEITUANDO O CAPITAL SOCIAL EM RELAÇÃO A CRIANÇAS E JOVENS: É DIFERENTE PARA MENINAS?"
}

\author{
VIRGINIA MORROW*
}

\begin{abstract}
RESUMO: Este artigo descreve um projeto de pesquisa que explorou a relevância da definição de Putnam (1993) de capital social (como algo que consiste de redes sociais, normas de confiança, reciprocidade, engajamento cívico e participação em comunidades) com crianças e jovens de áreas socialmente desfavorecidas. O artigo também apresenta dados de um estudo sociológico empírico que buscou explorar o significado e a relevância de diferentes aspectos do "capital social" para jovens de 12 a 15 anos que vivem em duas áreas carentes de uma cidade no sudeste da Inglaterra. Baseia-se em descriçōes que os jovens fazem de seu dia-a-dia e concentra-se em quatro elementos: relatos sobre os pais e a centralidade das mães, diferenças de gênero em relatos sobre o significado e a natureza da amizade, diferenças de gênero em experiências de espaços do bairro e recursos locais e diferenças de gênero nas aspiraçôes dos jovens para o futuro.
\end{abstract}

Palavras-chave: Infância. Capital social. Gênero.

\section{CONCEPTUALIZING SOCIAL CAPITAL IN RELATION TO CHILDREN AND YOUNG PEOPLE: IS IT DIFFERENT FOR GIRLS?}

ABSTRACT: This paper describes a research project that explored the relevance of Putnam's (1993) definition of social capital (as consisting of social networks, norms of trust, reciprocity, civic engagement and participation in communities) with children and young people in disadvantaged areas. Also, the paper presents data from an empirical sociological study that attempted to explore the meaning

\footnotetext{
* Tradução de Márcia Barroso, com revisão técnica de Fernanda Müller.

** PhD, professora e pesquisadora, coordenadora do Mestrado em Estudos da Infância, do Instituto de Educação da Universidade de Londres. E-mail: v.morrow@ioe.ac.uk
} 
and relevance of different aspects of "social capital" for 12-15 year olds living in two deprived areas of a town in SE England. It is based on young people's descriptions of their everyday lives, and focuses on four elements: accounts of parents and the centrality of mothers; gender differences in accounts of the meaning and nature of friendship; gender differences in experiences of neighbourhood spaces and local facilities; and gender differences in young people's aspirations for the future.

Key words: Childhood. Social capital. Gender.

\section{Introdução e histórico}

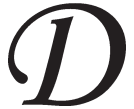

esde 1998, no Reino Unido, há um grande interesse em capital social, tanto em nível político como de pesquisa. No final da década de 1990, a Agência de Desenvolvimento de Saúde Health Development Agency (então HEA, a subdivisão de promoção de saúde do Departamento de Saúde da Inglaterra e País de Gales) - autorizou uma série de projetos de pesquisa qualitativa e quantitativa que foram desenvolvidos para testar, medir ou explorar a relação entre capital social e saúde em termos gerais. A definição de "capital social" neste trabalho é baseada no conceito de Putnam (1993), como algo que consiste de redes sociais e comunitárias, normas de cooperação, reciprocidade e confiança, identidade comunitária e senso de pertencimento a uma determinada comunidade e engajamento cívico ou participação.

Num ensaio crítico anterior, sugeri que o conceito de Putnam era problemático por várias razões (Morrow, 1999), mas particularmente em relação às crianças, uma vez que: 1) ignorava os efeitos de gênero, com a exceção de retratar as conseqüências do trabalho feminino como sendo negativas, tanto para a coesão da comunidade como para as crianças; 2) o trabalho feminino na criação e manutenção de redes sociais/capital social acabava ficando invisível; 3) pesquisas norte-americanas (particularmente derivadas de Coleman, 1988) focaram os "efeitos da estrutura familiar" nas crianças - uma visão controladora dos efeitos dos pais sobre as crianças, com ênfase na habilidade dos mesmos de investir no bem-estar e/ou futuro dos filhos (vide também Edwards et al., 2003, Blaxter \& Hughes, 2000). Como ressalta Molyneux (2002, p. 183), Putnam 
(...) freqüentemente endossa "a família" como o melhor locus de capital social a ser trabalhado e fortalecido. Poucos discordariam disso, mas muito depende de como isso é interpretado e o que se quer dizer com "a família". Em boa parte dessa literatura, a família é tratada normativamente como uma unidade onde pouco ou nada é considerado das divisões de trabalho por gênero e de poder dentro delas.

Os "pais", na literatura sobre capital social, geralmente não são diferenciados, e isso mascara que a maior parte da "paternidade/maternidade" tende a ser exercida pelas mães (Breugel \& Warren, 2003); é claro que isso é reconhecido há muito tempo em pesquisas feministas (Reay, 2002).

Argumentei que poderia ser utilizada uma conceitualização mais ativa sobre as crianças para explorar como elas causam, geram ou negociam seu próprio capital social, ou mesmo fazem conexóes para seus pais, ou até fornecem suporte ativo para eles. Em outras palavras, a agência das crianças, constrangida como é, não foi enfatizada nas pesquisas americanas, e elas aparecem como fardos passivos sobre o tempo dos adultos. Outros estudos americanos focalizam na "quantidade" de capital social, ao invés da "qualidade". Por exemplo, Coleman e outros autores utilizaram o número de irmãos como indicação de falta de capital social, com o argumento de que quanto mais crianças numa família, mais diluída é a carga de atenção dada a cada criança, o que produz resultados educacionais piores. Este argumento ignora o quanto os irmãos podem interagir para apoiar uns aos outros. Muitos dos estudos que "medem" capital social parecem assumir que filhos únicos são influenciados somente pela estrutura familiar e pela escola. Não se leva em conta o contexto social mais amplo, como grupos de amigos, redes sociais, atividades extra-escolares, como trabalho remunerado, e atividades das crianças em suas comunidades. Nem se presta atenção aos constrangimentos estruturais e como estes impactam no capital social. Esses constrangimentos podem ser diferenciados de acordo com o gênero, a etnia e o local.

Também sugeri que o trabalho mais complexo e contextualizado de Bourdieu sobre diferentes formas de capital interligadas, poderia ser utilmente aplicado em pesquisas que procurassem relacionar o contexto social do dia-a-dia das crianças, fosse ele sua casa, a escola ou a vizinhança, à saúde/bem-estar (Bourdieu, 1986). Se, por um lado, Bourdieu reconheceu que as mulheres são responsáveis por 
manter as relações afetivas/familiares (Reay, 2002), por outro, ele não utilizou o conceito de "capital emocional" em relação ao gênero. Nowotny (1981) sugere que, para homens e mulheres, pode haver diferentes regras para a conversão de capital, o que está relacionado à concentração (histórica) das mulheres no âmbito privado. Ela desenvolve o conceito de "capital emocional" como "conhecimento, contatos e relações, bem como habilidades e vantagens emocionalmente valorizadas, que estejam envolvidos em qualquer rede social caracterizada ao menos parcialmente por laços afetivos". O capital emocional pode ser compreendido como "o estoque de recursos emocionais que é construído ao longo do tempo nas famílias e ao qual as crianças podem recorrer" (Reay, 2002, p. 6).

De qualquer forma, parece que as formulações sobre capital social baseadas no trabalho de Putnam foram um tanto silenciosas quanto ao gênero em relação aos adultos; ou (pior) patologizando pais solteiros ou separados (90\% dos quais são mães) e seus filhos. Como seria o quadro do ponto de vista das crianças? Os diferentes elementos do "capital social” operam diferentemente de acordo com o gênero na infância?

\section{Quadros conceituais}

Dois quadros teóricos direcionam a pesquisa aqui descrita. O primeiro foi a emergente sociologia da infância, baseada no trabalho de dois antropólogos sociais britânicos, Allison James e Alan Prout (1990; vide também Mayall, 2002). Eles argumentam que precisamos evoluir para além dos modelos psicológicos que constroem a infância como um período de desenvolvimento e socialização. Precisamos ver as crianças como agentes sociais ativos que, pelo menos num nível micro, moldam as estruturas e os processos ao seu redor e cujas relações sociais merecem estudo em seu próprio direito. O segundo paradigma foi o fio condutor da "pesquisa de bem-estar" (Williams et al., 1999) que busca incorporar o contexto social à pesquisa na área de saúde (Macintyre et al., 1993) e explorar a importância do "lugar" e do "conhecimento leigo" em teorias e pesquisas sobre desigualdades em saúde (Popay et al., 1998). Esses dois paradigmas formam a base para o presente estudo, explorando as experiências subjetivas das crianças nas suas vizinhanças, sua qualidade de vida (e, essencialmente, seu bemestar/sua saúde), a natureza de suas redes sociais e a participação em suas comunidades. 


\section{Exemplo empírico}

A pesquisa ${ }^{1}$ foi conduzida em duas escolas em bairros relativamente carentes de uma cidade no sudeste da Inglaterra (uma área chamada de "Springtown", onde as crianças escolheram seus próprios pseudônimos; o local também foi escolhido para aliar outro estudo do HEA sobre adultos e capital social). Um dos bairros era uma área de ocupação desordenada na periferia da cidade, com casas e fábricas do período pós-guerra; o segundo era uma mescla do desenvolvimento industrial e do desenvolvimento habitacional no estilo vitoriano, dos períodos entre guerras e pós-guerra. A amostra abrangeu 101 meninos e meninas de duas faixas etárias: de 12 a 13 anos e de 14 a 15 anos, com uma proporção significativa de minorias étnicas.

Foi utilizada uma combinação de métodos de pesquisa qualitativa para explorar as experiências subjetivas das crianças em suas vizinhanças, suas experiências vividas no dia-a-dia, sua qualidade de vida e a natureza de suas redes sociais. Isto incluiu métodos estruturados, na forma de relatos escritos, de forma a elucidar informaçôes pessoais sobre amizade e redes sociais. As crianças também escreveram sobre o que fazem quando não estão na escola, o que forneceu dados sobre as situaçôes de independência e responsabilidade, associação a clubes e atividades extra-escolares, trabalho (para a família, remunerado e doméstico) e atividades de lazer. Elas também descreveram brevemente suas aspiraçōes profissionais para o futuro, e se já conheciam alguém que fazia esse tipo de trabalho. Um garoto de 14 anos da Escola 2 foi entrevistado. Também foram utilizados métodos visuais. Alunos do $10^{\circ}$ ano, ${ }^{2}$ individualmente ou em grupos, foram solicitados a fotografar lugares importantes para eles, usando câmeras descartáveis, e depois a descrever por que esses lugares eram importantes (isso gerou cerca de 100 fotos de seus ambientes). Crianças do $8^{\circ}$ ano desenharam mapas. Finamente, discussōes em grupo foram conduzidas para explorar o uso que faziam de suas vizinhanças e as percepções que tinham delas e da cidade, além de suas percepções das imagens no noticiário sobre seus ambientes e seu grupo etário. Elas discutiram também como seus ambientes poderiam ser melhorados e se tinham "voz ativa" em decisōes que são tomadas nas suas escolas e nas suas vizinhanças (participação).

Diferenças de gênero ficaram aparentes em alguns, mas não em todos os dados da pesquisa. Este trabalho está estruturado em torno das questôes da pesquisa, e as diferenças de gênero (quando detectadas) são 
exploradas em cada ponto: redes sociais, confiança e reciprocidade, visões do local e engajamento/participação cívica. Minhas conclusões são bastante cautelosas e não é minha intenção dar excesso de ênfase ao caso, já que, no tocante à interação gênero-etnia/idade, ficou bem claro nos relatos das crianças que cada "identidade" veio à tona de diferentes maneiras e era específica do contexto. Concluo que o gênero é relevante como princípio estruturador em certos pontos, mas não em outros, e que é importante ver que as crianças (assim como os adultos) têm múltiplas identidades e que são específicas do contexto.

Redes sociais: duas partes

\section{Redes familiares e a qualidade dos relacionamentos}

Os pais, especialmente as mães, são muito importantes para os dois grupos etários, e o trabalho emocional que as mães fazem foi claramente percebido e reconhecido pelas crianças, especialmente pelas meninas. Praticamente todos os comentários escritos das crianças sobre suas famílias (especialmente sobre suas mães) foram positivos e isso aparentemente é independente da estrutura familiar. Não lhes foi perguntado diretamente sobre estrutura familiar, mas às vezes essa informação foi descrita de maneira casual: “(...) as pessoas mais importantes para mim são minha mãe e meu melhor amigo da escola. Minha mãe, porque ela sempre consegue me aturar e tomar conta de mim e do meu irmão sozinha. Meu pai se divorciou dela há 5 ou 6 anos. Eu ainda o vejo de vez em quando, mas não o tempo todo" (Jody, de 14 anos).

Brenda, de 14 anos, descreveu: "A pessoa mais importante da minha vida é a minha mãe. Ela me criou e me fez ser do jeito que eu sou. Meu pai não me criou porque ele e minha mãe são divorciados, ele saiu de casa quando eu tinha dois anos de idade e eu não o vejo muito".

Cameron, de 13 anos, escreveu: "a pessoa mais importante da minha vida é a minha mãe. Ela é quem mais me entende". Asa May, de 13 anos, escreveu: "Minha mãe é muito importante para mim no momento porque está para ter um bebê no início de julho (...). Meu pai é importante porque eu não vivo com ele e gosto de vê-lo o máximo que eu posso". Em seu mapa, ela havia feito um desenho onde escreveu "Área da Titia, da Ann e do Papai", separadas de "Minha área" e "Área da Vovó". Safina, 
de 13 anos, descreveu: "Depois da escola, eu vou à mesquita, depois volto para casa, cuido dos meus 3 irmãos mais novos e ajudo minha mãe a limpar e arrumar a casa. A coisa mais importante é a Mamãe”. Mayall (2002, p. 52) percebeu, em seu estudo, como garotas muçulmanas "tinham uma compreensão clara e generificada sobre como sua vida deveria ser vivida agora e no futuro, baseada nos ensinamentos islâmicos".

Outras garotas mencionaram como suas mães eram importantes por uma série de razões; por exemplo, porque "ela é a única pessoa que eu tenho para conversar, e ela é amorosa, atenciosa e muito boa"; "ela faz tudo para mim"; "ela... sempre me apóia quando estou doente e sempre que eu preciso"; "ela é quem mais me entende". Shenna, de 12 anos, relata: "Minha mãe é importante porque ela se preocupa com tudo o que eu faço, por exemplo, se eu fico na porta de casa com meus amigos". Uma garota resumiu tudo assim: "Bem, minha mãe é a coisa mais, mais, mais importante da minha vida, porque só se tem uma mãe. Minha mãe é importante para mim porque eu sei que posso ir falar com ela sobre qualquer coisa e que ela geralmente entende o que eu enfrento na vida”.

Os garotos foram muito menos acessíveis sobre os diferentes papéis das mães e dos pais e tinham uma tendência a não separar um do outro, embora alguns tenham especificado que suas mães eram importantes, "por causa das coisas que ela faz por mim e pela família", ou: "ela me ajuda muito". Um outro garoto descreveu como ele faz sua tarefa de casa "com a Mamãe". Nenhum deles descreveu apoio emocional mais íntimo por parte das mães da mesma maneira que as garotas. Esses exemplos sugerem que as demandas e provisōes de apoio social e emocional (um elemento do capital social) nas famílias, ao longo das geraçóes, podem ser diferenciadas de acordo com o gênero, e refletem normas sociais sobre quem assume o cuidado das crianças, com quem mais provavelmente ficam as crianças após um divórcio e quem mais provavelmente fica "disponível" para "tomar conta" das crianças. Os relatos das crianças não refletem imagens que são comuns em pesquisas sobre capital social, que vêem as famílias de pais solteiros ou separados como "problemáticas", ou até mesmo deficientes.

\section{Aspirações e redes sociais}

Pesquisas anteriores têm mostrado que as chances econômicas dos indivíduos adultos são afetadas pela sua associação à um grupo 
Conceituando o capital social em relação a crianças e jovens: é diferente para meninas?

familiar (Grieco, 1987), mas não há muita pesquisa sobre como os jovens conseguem seu primeiro e subseqüente emprego através de redes informais. Eu pedi às crianças que escrevessem se elas sabiam o que queriam fazer quando saíssem da escola e se já conheciam alguém fazendo esse tipo de trabalho (para tentar explorar suas redes sociais e fontes potenciais de informações sobre empregos; $\mathrm{n}=78$ responderam à pergunta e $n=46$ conheciam alguém realizando o trabalho a que aspiravam). Em ambas as escolas, essas respostas (em sua maioria) se diferenciaram de acordo com o gênero, e quando as crianças tinham modelos/fontes de informação eram invariavelmente do mesmo gênero que elas próprias. As redes familiares pareciam ser a fonte de informação principal e orientação sobre empregos e planos futuros para a educação (embora eu queira novamente ser um pouco cautelosa neste ponto, uma vez que pode ser prematuro perguntar a uma criança de 12 ou 13 anos o que ela quer fazer após sair da escola).

\section{Alguns exemplos de garotas}

"Minha irmã é babá e eu também quero ser" (garota de 13 anos de idade). "Quando eu sair da escola, quero ser cabeleireira. Minha tia tem um salão. Também quero trabalhar em um salão de beleza" (garota de 13 anos). "Quando eu sair da escola, quero fazer faculdade por um ano. Quero estudar enfermagem infantil e depois conseguir um emprego numa creche ou num berçário. Eu conheço uma senhora que mora logo após a esquina da minha rua e que cuida de crianças e é experiente" (Sandy, de 15 anos). Sabrina, de 13 anos, contou numa discussão de grupo que trabalhou como babá para uma família da vizinhança: "Eu sou babá da garota que mora bem em frente à minha casa, sabe... a tia dela foi para o Paquistão, junto com toda a família, menos o avô; então eu cuidava dela todos os dias depois da escola. Isso foi quando ela tinha uns três anos". Ela também escreveu: "Eu quero ser enfermeira ou advogada. A tia da garota de quem eu cuido é enfermeira. Ou então advogada, porque a irmã da melhor amiga da minha irmã é advogada e sempre recebe certificados da universidade. Ela é tão inteligente!". Havia algumas garotas com aspirações mais elevadas, particularmente na Escola 2. Uma queria ser "psicóloga forense", outra, "veterinária", outra, "jornalista". 


\section{Exemplos dos garotos}

"Quero ser construtor; meu pai é construtor" (garoto de 12 anos); "Quando eu sair da escola, espero trabalhar no campo do direito, possivelmente como advogado. Meu primo não é advogado, mas é um funcionário do tribunal" (Dave, de 14 anos). James, de 14 anos, de West Ward (um bairro): "Eu gostaria de fazer programação ou alguma coisa relacionada a computadores. Conheço uma pessoa que trabalha com computadores. É o nosso vizinho de frente e ele é um bom amigo nosso". Tom, de 15 anos, falou de suas expectativas: "Espero ser pintor e decorador quando sair da escola. Meu cunhado fazia isso e eu o ajudava. É por isso que me interesso por esse tipo de trabalho". Ajit, de 15 anos, descreveu expectativas suas: "fazer um curso, me aperfeiçoar, ir para a universidade, conseguir um certificado em micro-eletrônica e administrar uma empresa. Meu tio dos EUA tem uma empresa de chips para impressoras". Jagu disse: "Quando eu sair da escola, espero ir para a faculdade, estudar e fazer cursos de aperfeiçoamento, não sei bem quais. Eu conheço muita gente que vai para a faculdade, como meu irmão mais velho, os amigos dele e os irmãos dos meus amigos”. Outros garotos afirmaram querer ser pilotos e um deles queria ser mecânico ("É que meu terceiro irmão mais velho é mecânico"). Não há exemplos de garotos querendo assumir ocupações "femininas".

Discuti brevemente com os grupos mais velhos (E2), questionando se eles achavam que a escola os preparava para a vida, e uma garota comentou:

Algumas pessoas não sabem o que querem ser; não sabem o que as espera lá fora, (...) deveriam nos ensinar sobre todos os tipos de oportunidades, como as profissões e essas coisas assim, tudo o que você precisa para tê-las, o que elas realmente envolvem, porque você pode achar que quer ser veterinário, por exemplo, e não ter a menor idéia do que você precisa fazer.

Ela parece consciente de que as fontes de informação disponíveis são um tanto limitadas, e não é de se surpreender que tantas crianças no estudo tivessem o que se pode ser visto como uma reflexão realista das oportunidades existentes para elas em suas vizinhanças e/ou uma reflexão das experiências de pessoas próximas. Suas aspirações imaginadas também refletiram a natureza generificada das funções no trabalho. 
Conceituando o capital social em relação a crianças e jovens: é diferente para meninas?

Por exemplo, várias garotas disseram ser babás de parentes ou de crianças da vizinhança, como uma maneira de ganhar dinheiro. Então, em termos de capital social, as crianças pareciam estar conscientes das fontes potenciais de informação, a maioria delas localizada nas redes familiares e, ocasionalmente, na vizinhança, e estas se diferenciavam conforme o gênero.

\section{Confiança e reciprocidade: redes sociais informais}

Diferentemente das redes familiares, as redes sociais consistem basicamente de conjuntos informais de redes baseadas em grupos de amigos da escola ou da vizinhança. A ligação a associações voluntárias (tão centrais na argumentação de Putnam) era bem limitada e muito específica, de acordo com o gênero: seis garotos mencionaram serem membros de um time de futebol e algumas garotas mencionaram que assistiam a jogos de futebol. Uma garota afirmou freqüentar um clube, um garoto mencionou o quanto era importante a sua ligação ao time de rugby no Corpo de Treinamento Aéreo e fotografou um armário com um troféu. Dez crianças afirmaram usar os clubes locais de jovens. As crianças mencionaram muito o fato de se divertirem com amigos e/ou participar de várias atividades informais esportivas e de lazer, incluindo patinação, natação e (até) boliche, demonstrando que os amigos eram incrivelmente importantes por uma série de razões. Em muitos casos, os sentimentos das crianças em relação ao local onde viviam dependiam da proximidade dos amigos, como Maggie, E2, de 15 anos, afirmou: "Eu adoro a minha casa e o meu bairro, porque existem três parques perto de mim, o centro fica a cinco minutos de caminhada, a escola é perto e eu posso visitar meus amigos sem ter que pegar um ônibus ou andar muito. A maioria dos meus amigos mora em Hill Ward ou na minha área”. Não ter amigos morando perto era um problema e isso parecia mais marcante na Escola 1, que, como visto acima, ficava em um local periférico e calmo, com poucos recursos para os jovens. E eram principalmente as meninas quem afirmavam isso, o que refletia restriçôes à sua mobilidade. Por exemplo, Olanda, de 14 anos, da E1, contou: "Eu estou razoavelmente feliz com o local onde eu moro, mas eu preferiria morar na minha antiga casa... isso porque muitos dos meus amigos mais próximos moram lá. Eu geralmente vou a pé até lá depois da escola. Seria muito menos complicado se eu morasse lá, perto deles”. Jade, de 14 anos, da E1, afirmou: 
"Eu conheço a minha melhor amiga há uns dez anos... ela é como se fosse minha irmã... eu moro em West Ward há dez anos e [minha melhor amiga] mora em frente à minha casa”. Rebecca, (de 13 anos, E1) descreveu como não gostava de sua vizinhança:

(...) é chato, não tem muitas pessoas da minha idade morando por aqui. Como a minha melhor amiga se mudou, ela mora a 10 minutos da minha casa, mas é muito longe para ir até lá a pé todo dia. Nós sempre fomos as melhores amigas e nunca brigamos. Fazemos muitas coisas juntas, e ela vem passar as férias comigo este ano. Mal posso esperar.

As crianças definiram amizade atráves dos seus relatos escritos. A intenção, com essas definições, era elaborar um insight acerca das crenças e normas das crianças sobre amizade. Setenta crianças responderam à pergunta e quase metade das respostas $(\mathrm{n}=33)$ continha a palavra "confiança" como um elemento da amizade. Outros componentes eram: suporte emocional, o fato de saber ouvir, respeito, o fato de estar presente, dando conselhos, oferecendo ajuda, cuidado, reciprocidade, alguém com quem compartilhar, dividir segredos e se divertir. As diferenças de gênero não foram marcantes nas definiçōes, embora as meninas tendessem a dar muito mais detalhes que os meninos. A tendência dos garotos era definir a amizade bem brevemente, usando noções de diversão e de ter alguém com quem sair, embora alguns refletissem a importância de ter alguém que os ouvisse e em quem pudessem confiar, por exemplo: "Um amigo é uma pessoa com quem você pode falar, que te ouve e que não vai rir nem contar aquilo a ninguém. Um amigo é uma pessoa em quem você pode confiar" (Peter, de 12 anos, E1). Três garotos, dois da Escola 1 e um da Escola 2, usaram a expressão "um ombro para chorar" em suas definições escritas. Até certo ponto, os garotos utilizaram uma linguagem diferente. Além de falar em ficar com a "galera", se divertir juntos, usam também a noção de apoio não-crítico, numa maneira semelhante à das garotas. Isso pode ser decorrência dos métodos utilizados. As crianças puderam responder livremente por escrito, sendo a escrita realizada privadamente. Será que os garotos teriam descrito a importância emocional de seus amigos se a pergunta tivesse sido feita em discussões em grupo, onde pressões para agir "como garotos" poderiam ter constrangido suas respostas?

As garotas tenderam a classificar suas amigas como "amigas íntimas", "amigas muito íntimas", "amigas mais antigas", "melhores amigas" ou até "minha grande melhor amiga", e não grupos de amigas. Os temas 
Conceituando o capital social em relação a crianças e jovens: é diferente para meninas?

de apoio não-crítico, confiança e "presença constante" foram freqüentemente mencionados quando as garotas descreveram o porquê da importância de suas amigas. Kellie, de 12 anos, da E1, descreveu: "Eu conheço Stacey há dois anos e ela é a minha mais que melhor amiga do mundo. Ela é atenciosa e eu gosto dela. Ela é boa e é o tipo de pessoa com quem eu posso falar sobre os meus problemas da escola ou de casa”. Carly, de 13 anos, da E2, relata: "Minha melhor amiga, Angelina, é importante para mim porque eu posso contar a ela segredos, e ela não vai contar a ninguém”. Isabelle, de 15 anos, E2, contou que tem amigos com quem se encontra e que já haviam saído da escola: "Eles são bem importantes para mim porque eu posso contar a eles sobre discussões/coisas que me chatearam na escola e eles ajudam porque estão olhando para o problema de fora; não estão envolvidos na situação". Maggie, de 15 anos, E2, relatou: "Embora todos os meus amigos sejam importantes para mim, alguns são muito mais importantes que outros. Meus amigos mais íntimos ou os mais antigos são os mais importantes, porque eles sempre estiveram presentes para me ajudar e apoiar". Uma garota, Dion, de 13 anos, da E2, escreveu: "Meus amigos são importantes. Uma das minhas amigas é como minha irmã". Os amigos também eram significativos na escola durante o dia escolar. Por exemplo, Kerry, de 14 anos, E1, relatou: "Na escola, quando não estou em aula, eu fico com minha melhor amiga Sally e minha outra amiga Becky, com quem eu venho a pé para a escola. Nós normalmente só andamos por aí, falando sobre coisas de meninas". Isabelle, de 15 anos, E2, contou: "Eu tenho amigos na escola que são importantes para mim, e nós conversamos o tempo todo na escola".

Os garotos, em geral, listavam nomes de amigos ao invés de classificá-los como "melhores amigos", embora houvesse exceções a isso. Freqüentemente, assume-se que os as amizades de garotos preenchem uma função diferente da que seria a das meninas. Amigos, para eles, têm a função de dar contribuições ativas, como apoiar ou defender uns aos outros, e fazer coisas juntos, o que é evidenciado nas descriçôes do que eles fazem fora da escola, como esportes e outras atividades de lazer. Por exemplo, James, de 14 anos, escreveu: "se eu não tivesse amigos, eu não conseguiria fazer coisas emocionantes, como ir a lugares legais com eles, nadar etc.”. No entanto, como se pôde perceber, alguns garotos descreveram como seus amigos são importantes para eles porque os ouviam, eram leais e eram pessoas em quem eles podiam confiar. Alguns conheciam seus amigos há muito tempo. Bob, de 14 anos, escreveu: "O amigo que eu conheço há mais 
tempo é o Dave. Nós somos amigos desde a educação infantil. Ele é um bom amigo e eu respeito muito a opinião dele". Dave (que era da mesma classe) escreveu: "A coisa mais importante para mim é a família, mas na escola e fora dela, o mais importante para mim são meus amigos. Alguns deles, como o Bob e o Fred, eu conheço há nove ou dez anos... um amigo é alguém que está sempre presente para te ajudar, quando você mais precisa. Ele não te abandona em tempos difíceis. Os amigos são para você conversar, estar por perto e dar apoio". Joseph, de 15 anos, da E2, descreveu coisas que gostava de fazer com amigos: de manhã, "chamar meu amigo para ir para a escola", à noite "sair com os amigos para festas" e, aos finais de semana: "me levantar à tarde e sair com amigos, principalmente para parques e para o centro da cidade. Meus amigos e minha família são as pessoas mais importantes da minha vida. Eles sempre estão por perto quando eu preciso. Eu confio neles".

Houve muito poucos exemplos de amizades íntimas entre pessoas de gêneros diferentes, embora as listas de amigos das crianças geralmente incluíssem nomes de meninos e meninas. Um dos meninos explicou: "Minha amiga Heather é importante para mim porque eu não vejo nenhum outro amigo nos finais de semana e eu posso falar com ela sobre coisas que eu não tenho para quem falar. Conheço a Heather há um bom tempo, uns 4 anos. Eu a conheço porque a mãe dela é amiga da minha mãe" (Bart, de 13 anos). Esse é um exemplo da ligação próxima entre as redes de mães e de crianças.

Em resumo, as redes sociais informais parecem funcionar de maneira diferente para meninos e meninas. As meninas reconhecem explicitamente a amizade como fonte de apoio emocional, enquanto os meninos parecem valorizar seus amigos para atividades em comum e esportes. Contudo, é importante não supervalorizar a diferença aqui, uma vez que alguns meninos obviamente entendem seus amigos como uma fonte de pertencimento e confiança. E também há um aspecto negativo da amizade: muito poucos meninos e meninas mencionaram ficar magoados por ter brigado com um amigo ou uma amiga.

\section{Identidade comunitária e uso do espaço público}

Pesquisas anteriores mostraram que as garotas tendem a ter acesso mais restrito a espaços públicos, devido aos receios dos pais e conceitos 
Conceituando o capital social em relação a crianças e jovens: é diferente para meninas?

de gênero estereotipados (Valentine 1997). As garotas do estudo não eram confinadas em casa. Elas afirmaram passar bastante tempo em parques e nas ruas. No entanto, como Matthews (2003) também descobriu, as meninas pareciam mais receosas que os meninos, e os relatos diferiam de acordo com o gênero, particularmente no grupo das meninas mais velhas, que geralmente (mas não sempre) falavam de ameaças de abuso sexual e ansiedade com relação aos espaços públicos (infelizmente, não era o caso de "perigo desconhecido", como freqüentemente se afirma na literatura: na época da pesquisa, um estuprador em série estava atacando mulheres e meninas na cidade). Natalie, de 12 anos, comentou: "Eu não me sinto segura onde moro, porque tem uns apartamentos perto de nós, e nós soubemos que algumas pessoas foram realmente mortas nesses apartamentos, e coisas assim, e tem uns estupradores no bairro... não faz muito tempo, e eu não me sinto muito segura no meu bairro".

E, num grupo de faixa etária mais avançada, Amy descreveu como:

(...) é que uma pessoa foi atacada lá [no parque local], então, isso te deixa com medo de ir lá, e foi em plena luz do dia, então só Deus sabe como seria às 10 horas da noite (...). Eu moro num tipo de rua isolada, quase ninguém anda nessa rua e não tem nada lá, só um parquinho. Mas uma pessoa foi atacada, e você fica com medo de ir lá. Então, se eu tivesse uns 20 anos, e tivesse dois filhos pequenos, eu não teria nenhum lugar seguro para levá-los [nesse bairro].

O comentário de Amy também demonstra os seus pensamentos em relação aos outros (sobre isso, ver Gilligan, 1982 e 1990). As garotas, em geral, mostravam mais preocupação com os outros do que os garotos, geralmente expressando um forte sentimento de moralidade em seus comentários. Também, com bastante freqüência, demonstravam uma preocupação em especial com crianças pequenas. Por exemplo, um dos temas recorrentes foram placas com os dizeres: "proibido jogar bola", que os proibiam de jogar perto de suas casas nos gramados, de uso coletivo. As placas foram fotografadas, sinalizadas em mapas e discutidas em grupos. Isabelle, de 15 anos, explicou sua foto: "Esta é uma placa que está numa área gramada da minha rua. Ela impede que as crianças organizem brincadeiras típicas, mas crianças pequenas precisam de um lugar para jogar... elas talvez não sejam autorizadas a ir ao parque".

Em uma discussão, outra garota (E2, 10 ano) relatou: "Do lado de fora da minha casa, nós temos uma área verde, e colocaram um aviso 
dizendo; 'proibido jogar bola'. Nós tínhamos duas árvores que usávamos como gol e, aí, veio uma mulher que sempre reclamava, que foi até a prefeitura, fez retirarem as árvores e colocarem arbustos na grama para que a gente não pudesse jogar. A gente jogava rounders ${ }^{3}$ e outras coisas". Outra garota, Katie, de 13 anos, incluiu a placa no seu mapa e escreveu embaixo: "injusto". O fato de as garotas terem enfatizado isso talvez reflita os constrangimentos sobre a sua mobilidade: pode ser que elas queiram jogar mais perto de casa e não nos parques (onde o futebol é dominante). Como disse uma garota de 12 anos (E2): "Eu tenho que voltar para casa às 20 horas. Se eu estou na minha rua, posso entrar às 21 horas, mais ou menos, mas se eu estou em algum lugar que minha mãe não conhece, esse tipo de coisa, quando eu estou fora de casa com meus amigos, tenho que voltar às $20 \mathrm{~h}$ ".

Foram principalmente as meninas que falaram de seus pais cuidando delas. Uma garota que entregava jornal explicou que seus pais a ajudavam nisso: "Minha mãe e meu pai são superprotetores, então eles entregam o jornal comigo". Cameron (12 anos) explicou:

Minha mãe não gosta que eu vá para [outra parte da cidade] sozinha, porque você nunca sabe como é, tem um estuprador andando pela área no momento, então é difícil. Porque você tem que observar onde está andando e você não tem permissão para andar em qualquer lugar sozinha; você tem que estar em um grupo. Se a polícia realmente fizesse alguma coisa para deter o estuprador, aí a gente poderia ir [ao parque].

Em uma das discussões em grupo, as meninas sentiam muito que as oportunidades de lazer, em termos de locais e atividades, eram destinadas aos meninos. "Não tem nada para as meninas: eles só ficam jogando futebol e basquete, então nem adianta ir lá” (Marissa, de 12 anos, E1).

Cameron (de 12 anos, E2) queixou-se de corridas de carro e descreveu como estas aconteciam: "Na minha área, tem uns garotos com um carro, e eles ficam correndo pela rua, freando e fazendo 'cavalinho de pau'. Eu estava levando minha prima para casa, a pé, e o carro subiu na calçada e quase a atropelou".

Ela sugeriu uma solução: "A maioria dos garotos na nossa área se interessa por carros e motos. Se eles pudessem aprender sobre mecânica, talvez saíssem das ruas". Houve um exemplo, numa discussão em grupo, de duas garotas descrevendo comportamento anti-social. Natalie (E1) 
Conceituando o capital social em relação a crianças e jovens: é diferente para meninas?

descreveu um incidente e admitiu ter "praticado vandalismo na ponte". Então Agnes disse: "Todo mundo vandalisa a nossa ponte". Havia um forte sentimento de que meninos e meninas se envolvem em problemas por estar "andando por aí nas ruas, sem ter nada para fazer".

Atalhos, trechos e caminhos distantes de ruas movimentadas eram muito importantes para as crianças, mas eram freqüentemente vistos como assustadores e desagradáveis. Uma garota (E2, de 12 ou 13 anos) descreveu:

Eu detesto andar pelas estações de metrô. Eu passo por duas no meu caminho para a escola e fico pensando: será que eu vou mesmo chegar à escola? Porque você nunca sabe se tem alguém parado num canto, sei lá, ou te seguindo... Eu detesto atravessar a estação. Minha irmã e eu corremos para atravessar, mas se eu estou com um grupo maior, aí, eu não ligo.

Alguns garotos também concordaram sobre esses aspectos problemáticos do espaço público. Algumas dificuldades específicas foram observadas entre jovens negros e de minorias étnicas, que se sentiam ameaçados não somente por grupos de jovens mais velhos, mas também pela "imparcialidade" da polícia. No entanto, em geral, os comentários das meninas sobre medo e segurança estão presentes na literatura sobre mulheres e segurança nas vizinhanças.

\section{Participação}

O último conjunto de perguntas explorou a intensidade da participação das crianças na tomada de decisóes na escola e na comunidade e, como houve uma experiência claramente compartilhada com base na idade, as diferenças de gênero não foram particularmente marcantes. A ênfase de Putnam na participação cívica como um aspecto vital do capital social é obviamente um tanto limitada no caso das crianças, uma vez que elas são posicionadas fora das estruturas democráticas pela sua própria natureza como "menores", embora o Relatório Better Together ${ }^{4}$ (Seminário Saguaro, 2000) $)^{5}$ sobre capital social nos EUA dedique um capítulo todo à "juventude" e reconheça que pessoas de 10 a 12 anos são "muito raramente incluídas na vida cívica americana, seja na tomada de decisões ou nos papéis de contribuição" e sugere que esse grupo é "maduro o suficiente para compreender obrigaçóes cívicas, mas permanece sendo muito jovem para formar hábitos cívicos". 
A participação das crianças na tomada de decisões em comunidade, no meu estudo, foi extremamente limitada. Apenas um garoto achou que poderia ir até a associação de moradores do seu bairro e fazer sugestôes sobre a sua vizinhança e, quando ele disse isso, outras crianças do grupo cochicharam: "Ah, mas aquele é um bairro chique". Se os representantes locais do Poder Legislativo viessem e perguntassem sobre os recursos locais, as crianças presumiam que seus pais seriam consultados, e não elas. Amy disse: "Eles mandam questionários para os nossos pais, mas não são os nossos pais que querem ir ao Clube dos Jovens, e sim nós. Então, é a nós que eles deveriam perguntar”. Uma garota comentou que ela sentia que eles deveriam ter voz na comunidade, porque, como ela disse: "O que acontece afeta a nós da mesma maneira que afeta os adultos, e parece que eles não pensam nisso ao tomar decisões". A prefeitura tinha recentemente iniciado um "Fórum Jovem”, mas as crianças do estudo não estavam sabendo disso:

Gemma: "Ninguém sabe disso, se existe um..."

Tamisha: "Eu acho que deveria existir um, mas..."

Miranda: "Mas eles escolheriam as pessoas que se destacam na escola e tudo mais, e elas não são pessoas comuns, são?"

Esses dados sugerem que a participação, no sentido de se estar ativamente envolvido em decisões que afetam as crianças em seus bairros, parece ser praticamente inexistente para elas. Mesmo em locais onde existiam estruturas supostamente democráticas, como os conselhos escolares, como foi o caso de uma das escolas do estudo, as crianças não pareciam estar experimentando "participação" através deles, e a exclusão que elas parecem sentir tem o potencial de limitar o seu senso de auto-eficiência e controle sobre seus ambientes (Morrow, 2000). Um dos problemas que esse grupo etário enfrenta é que ele não tem canais formais pelos quais se comunicar ou para canalizar suas energias em um recurso positivo para os seus bairros. Fóruns Jovens são a maneira mais comum de se trabalhar com as visões dos jovens, mas eles não necessariamente funcionam efetivamente (Fitzpatrick et al., 1998). O comentário de Miranda, acima, sugere que ela é bem consciente dos limites de participação e representação democrática. Um senso de participação poderia ser estimulado logo cedo ao se incluir jovens em processos de tomada de decisão, fossem eles em escolas ou bairros. Isso é 
reconhecido na literatura americana sobre capital social (Seminário Saguaro, 2000), mas ignoram-se as diferenças entre crianças e jovens e retrata-se um conceito raso e unitário de "juventude desafetada", e não se leva em consideração como essas diferenças podem afetar a vontade ou a capacidade de "participar". Além disso, há também implicações para escolas que já estão sob pressão para produzir resultados que sejam "mensuráveis" em notas de exames, e para o governo local, que está sob pressão para economizar dinheiro.

\section{Discussão}

É claro que meu estudo de pequena escala sofre muitas limitações, inclusive a questão da generalização dos achados. Além disso, os métodos utilizados na pesquisa podem ter gerado diferentes dados, de acordo com o gênero, uma vez que as masculinidades e feminilidades são exercidas no processo da pesquisa. $\mathrm{O}$ gênero ficou saliente em muitos pontos do estudo, parecendo espelhar ou prever as relações e práticas de gênero na idade adulta: em relatos sobre amizades, no reconhecimento do trabalho emocional das mães, em aspirações profissionais e na segurança dos bairros. Houve claras evidências de atitudes de responsabilidade nos relatos das garotas sobre cuidar de crianças nas suas famílias ou na vizinhança. Por outro lado, no que dizia respeito a ter voz ativa nas decisões das escolas e bairros, o que parecia estruturar as experiências dos jovens era o seu posicionamento social e suas desvantagens compartilhadas, ambos baseados em sua idade/ geração. Então, para concluir, eu respondo à pergunta que lancei a mim mesma: "O capital social é diferente para meninas? A resposta é sim, em determinados aspectos que são significativos, e não, em outros. $\mathrm{O}$ estudo enfatizou que as "crianças" não são uma categoria homogênea. O conceito de "capital social" precisa ser capaz de acomodar uma série de diferenças. Em termos de gênero, para as meninas, a segurança pessoal foi uma questão crucial, e o abuso sexual foi percebido (justificadamente, neste caso) como uma ameaça. Houve também intersecções com etnia (não discutidas neste trabalho): o medo da discriminação racial pode levar à exclusão social e emocional.

Em geral, o estudo destacou a maneira como vários constrangimentos espaciais e econômicos foram sentidos por este grupo etário, por exemplo, não tendo locais seguros para brincar, não podendo atravessar a rua por causa do trânsito, não tendo um lugar para onde ir além do shopping 
center, onde também são vistos com desconfiança, devido à falta de dinheiro. A possibilidade das crianças circularem livremente para participar de atividades com seus amigos foi constrangida pela geografia física do ambiente construído, questóes de segurança na comunidade e tráfego, normas dos pais sobre quanto as crianças podem sair de casa. Esses constrangimentos tendem a diferir de acordo com o gênero. $\mathrm{O}$ estudo também concluiu que, enquanto o capital social pode ser útil como uma ferramenta ou um dispositivo heurístico, ele também foi problemático por muitas razões, dentre as quais significado e mensuração (para mais discussões sobre vantagens e desvantagens de se utilizar o "capital social" em pesquisas e programas de ação política, ver Morrow, 2001b e 2001c).

\section{Formas plurais de capital social?}

Em Bowling Alone, Putnam (2000) enfatiza a centralidade de redes sociais no seu conceito de capital social e minimiza a importância dos outros elementos. Ele e outros autores sugeriram que há várias formas de capital social, como os de união e de articulação. Por exemplo, grupos podem ter um alto nível de capital social, que mantém a solidariedade no grupo ao unir seus integrantes, mas o mesmo grupo pode mostrar muito pouco do tipo de capital social que articula outras divisões, como gênero, classe social, etnia ou geração. O capital social bonding não contribui necessariamente para a coesão social. Por exemplo, o fato de as crianças andarem em "gangues" parece ter um efeito negativo de coesão social, pelo menos do ponto de vista dos outros, sejam eles crianças menores ou pessoas mais velhas (Campbell et al., 1999). Mas, no nível individual, as crianças precisam de ambas as formas de "capital social": "de articulação" (bridging) para o futuro, para capacitá-las a "fugir das desvantagens", e "de união" (bonding) para o seu apoio social e bem-estar emocional. De certa forma, as crianças têm uma condição ambígua ao existir no "aqui-e-agora" e no futuro. Os dados sobre aspiraçóes e redes refletem o seguinte: se os jovens vêem os membros de suas famílias (ou pessoas da vizinhança) como a principal fonte de informação sobre empregos, então é assim que as desigualdades sociais, inclusive as de gênero, são reproduzidas (daí a ênfase de Bourdieu na importância da família como lugar de reprodução) (Morrow, 2001c). Em segundo lugar, o "capital social" reside nas relações de amizade e grupos de pares, o que promove um senso de pertencer ao aqui-eagora. Outros autores sugeriram uma terceira forma de capital social, o 
Conceituando o capital social em relação a crianças e jovens: é diferente para meninas?

capital social "de conexão" (linking), que conecta ou articula grupos com outros mais influentes, possibilitando o acesso às estruturas de poder (Foley \& Edwards, 1999). Isso era algo que claramente faltava às crianças de Springtown. Molyneux, escrevendo no contexto da América Latina estudos de desenvolvimento - sugere que a presença do capital social no campo da ação política

(...) pode estar sinalizando uma fuga de agendas mais problemáticas (...) de cidadania e direitos, por um lado, e de provisões e políticas para garantir maior inclusão social, por outro. Enquanto as agendas baseadas em cidadania e direitos levantam questóes sobre políticas e titulações, e os debates sobre integração social e inclusão confrontam implicitamente questôes de políticas sociais, o capital social, focado em micro-fenômenos, levanta poucas questōes desafiadoras. É comum que ele ocupe um terreno no qual a política tipicamente só entra pela porta dos fundos, enquanto as desigualdades sociais são raramente confrontadas, seja na teoria ou na ação política. (Molyneux, 2002, p. 174)

O discurso do "capital social" corre o risco de evitar combater desigualdades, sejam elas alicerçadas no gênero ou em outras diferenças estruturais.

Recebido em setembro de 2006 e aprovado em março de 2007.

\section{Notas}

1. Detalhes sobre consideraçôes metodológicas e éticas, vide Morrow (2000, 2001a, 2001b, 2002).

2. N.R.: $\mathrm{Na}$ Inglaterra, a escola primária (primary school) é organizada da reception class ao $6^{\circ}$ ano, enquanto que a escola secundária (secondary school) compreende mais cinco anos (7, $8,9,10$ e 11). É esperado que os estudantes do $10^{\circ}$ ano tenham 14-15 anos.

3. Jogo semelhante ao baseball.

4. N.T.: Juntos é Melhor

5. N.R.: Informações no site <http://www.bettertogether.org>

\section{Referências bibliográficas}

BLAXTER, L.; HUGHES, C. Social capital: a critique. In: THOMPSON, J. (Ed.). Stretching the academy: the politics and practice of widening participation in higher education. Leicester: NIACE, 2000. 
BOURDIEU, P. The social space and the genesis of groups. Theory and Society, Dordrecht, v. 14, n. 6, p. 723-744, 1985.

BOURDIEU, P. The forms of capital. In: Richardson J.G. (Ed.). Handbook of theory and research for the sociology of education. New York: Greenwood, 1986.

BOURDIEU, P. Sociology in question. London: Sage, 1993.

BREUGEL, I.; WARREN, S. Family resources and community social capital as routes to valued employment in the UK?. Social Policy and Society, Cambridge, v. 2. n. 4, p. 319-328, oct. 2003.

CAMPBELL, C; WOOD, R.; KELLY, M. Social capital and health. London: Health Education Authority, 1999.

COLEMAN, J.S. Social capital in the creation of human capital. American Journal of Sociology, Chicago, n. 94 suppl., p. 95-120, 1988.

EDWARDS, R.; FRANKLIN, J.; HOLLAND, J. Families and social capital: exploring the issues. London: South Bank University, 2003. (Families \& social capital ESRC Research Group Working Paper, n. 1). Disponível em: <http://www/lsbu.ac.uk/families/workingpapers/ familieswp1.pdf>.

FITZPATRICK, S.; HASTINGS, A.; KINTREA, K. Including young people in urban regeneration: a lot to learn? Bristol: The Policy, 1998.

FOLEY, M.; EDWARDS, B. Is it time to disinvest in social capital? Journal of Public Policy, Cambridge, v. 19, n. 2, p. 141-173, 1999.

GIECO, M. Keeping it in the family: social networks and employment chances. London: RKP, 1987.

GILLIGAN, C. In a different voice: psychological theories and women's development. Cambridge, Mass.: Harvard University, 1982.

GILLIGAN, C. et al. Making connections: the relational worlds of adolescent girls. Cambridge, Mass.: Harvard University, 1990.

JAMES, A.; PROUT, A. Constructing and reconstructing childhood: contemporary issues in the sociological study of childhood. London: Falmer, 1990. 
Conceituando o capital social em relação a crianças e jovens: é diferente para meninas?

MAYALL, B. Towards a sociology for childhood: thinking from children's lives. Buckingham: Open University, 2002.

MACINTYRE, S.; MACIVER, S.; SOOMAN, A. Area, class and health: should we be focusing on places or people? Journal of Social Policy, Cambridge, v. 22, p. 2, p. 213-34, 1993.

MATTHEWS, H. The street as a liminal space: the barbed spaces of childhood. In: Christensen, P.; O’Brien, M. (Ed.). Children in the city: home, neighbourhood and community. London: Falmer, 2003.

MOLYNEUX, M. Gender and the silences of social capital: lessons from Latin America. Development and Change, Oxford, v. 33, n. 2, p. 167-188, 2002.

MORROW, V. Conceptualizing social capital in relation to the wellbeing of children and young people: a critical review. The Sociological Review, v. 47, n. 4, p. 744-765, 1999.

MORROW, V. 'We get played for fools': young people's accounts of community and institutional participation. In: Bull, J.; Ryan, H. (Ed.). Changing families, changing communities: researching health and well-being among children and young people. London: HEA, 2000.

MORROW, V. Using qualitative methods to elicit young people's perspectives on their environments: implications for community health promotion initiatives. Health Education Research: theory and practice, v. 16, n. 3, p. 255-268, 2001 a.

MORROW, V. Networks and neighbourhoods: children's and young people's perspectives. London: Health Development Agency, 2001b. Disponível em: <http://www.hdaonline.org.uk/downloads/pdfs/ netneigh.pdf>.

MORROW, V. Young people's explanations and experiences of social exclusion: retrieving Bourdieu's concept of social capital. International Journal of Sociology and Social Policy, Hull, v. 21, n. 4/6, p. 37-63, $2001 \mathrm{c}$.

NOWOTNY, H. Women in public life in Austria. In: Epstein, C.F.; Coser, R.L, (Ed.). Access to power: cross national studies of women and elites. London: Sage, 1981. 
POPAY, J.; WILLIAMS, G.; THOMAS, C.; GATRELL, T. Theorising inequalities in health: the place of lay knowledge. Sociology of Health and Illness, Boston, v. 20, n. 5, p. 619-644, 1998.

PUTNAM, R.D. Making democracy work: civic traditions in modern Italy. Princeton: Princeton University, 1993.

PUTNAM, R.D. Bowling alone: the collapse and revival of American community. New York: Simon \& Schuster, 2000.

REAY, D. Gendering Bourdieu's concept of capitals?: emotional capital, women and social class. Paper presented at Feminists Evaluate Bourdieu Conference, Manchester University, 2002.

SAGUARO. Seminar on Civic Engagement in America Better Together Report, 2002. Disponível em: <www.bettertogether.org>.

VALENTINE, G. "Oh yes I can”. "Oh no you can't": children and parent's understandings of kid's competence to negotiate public space safely. Antipode, Worcester, v. 29, n. 1, p. 65-89, 1997.

WILLIAMS, F.; POPAY, J.; OAKLEY, A. Changing paradigms of welfare. In: Williams, F.; Popay, J.; OAKLEY, A. (Ed.). Welfare research: a critical review. London: UCL, 1999. 